\title{
Device-associated infection rates in intensive care units of Brazilian hospitals: findings of the International Nosocomial Infection Control Consortium
}

\author{
Reinaldo Salomao, ${ }^{1}$ Victor D. Rosenthal, ${ }^{2}$ Gorki Grimberg, ${ }^{3}$ \\ Simone Nouer, ${ }^{4}$ Sergio Blecher, ${ }^{1}$ Silvia Buchner-Ferreira, ${ }^{2}$ \\ Rosa Vianna, ${ }^{4}$ and Maria Ângela Maretti-da-Silva ${ }^{1}$
}

Suggested citation

Salomao R, Rosenthal VD, Grimberg G, Nouer S, Blecher S, Buchner-Ferreira S, et al. Device-associated infection rates in intensive care units of Brazilian hospitals: findings of the International Nosocomial Infection Control Consortium. Rev Panam Salud Publica. 2008;24(3):195-202.

ABSTRACT Objectives. To measure device-associated infection (DAI) rates, microbiological profiles, bacterial resistance, extra length of stay, and attributable mortality in intensive care units (ICUs) in three Brazilian hospitals that are members of the International Nosocomial Infection Control Consortium (INICC).

Methods. Prospective cohort surveillance of DAIs was conducted in five ICUs in three city hospitals in Brazil by applying the definitions of the U.S. Centers for Disease Control and Prevention National Nosocomial Infections Surveillance System (CDC-NNIS).

Results. Between April 2003 and February 2006, 1031 patients hospitalized in five ICUs for an aggregate 10293 days acquired 307 DAIs, a rate of $29.8 \%$ or 29.8 DAIs per 1000 ICUdays. The ventilator-associated pneumonia (VAP) rate was 20.9 per 1000 ventilator-days; the rate for central venous catheter-associated bloodstream infections (CVC-BSI) was 9.1 per 1000 catheter-days; and the rate for catheter-associated urinary tract infections (CAUTI) was 9.6 per 1000 catheter-days. Ninety-five percent of all Staphylococcus aureus DAIs were caused by methicillin-resistant strains. Infections caused by Enterobacteriaceae were resistant to ceftriaxone in $96.7 \%$ of cases, resistant to ceftazidime in $79.3 \%$ of cases, and resistant to piperacillintazobactam in $85.7 \%$ of cases. Pseudomonas aeruginosa DAIs were resistant to ciprofloxacin in $71.3 \%$ of cases, resistant to ceftazidime in $75.5 \%$ of cases, and resistant to imipenem in $27.7 \%$ of cases. Patients with DAIs in the ICUs of the hospitals included in this study presented extra mortality rates of $15.3 \%(R R 1.79, P=0.0149)$ for $V A P, 27.8 \%(R R 2.44, P=0.0004)$ for CVC-BSI, and 10.7\% (RR 1.56, P = 0.2875) for CAUTI.

Conclusion. The DAI rates were high in the ICUs of the Brazilian hospitals included in this study. Patient safety can be improved through the implementation of an active infection control program comprising surveillance of DAIs and infection prevention guidelines. These actions should become a priority in every country.

Key words Bacterial infection; cross infection/epidemiology; drug resistance, bacterial; hospitals; infection control; infection control practitioners; intensive care units; length of stay; mortality; Brazil.

1 Division of Infection Control, Santa Marcelina Hospital, São Paulo, Brazil.

2 Department of Infection Control, Medical College of Buenos Aires, Buenos Aires, Argentina. Send correspondence to Dr. Victor Rosenthal, Lavalleja 305, Floor 9, Apt B, (1414) Buenos Aires, Argentina; e-mail: victor_rosenthal@inicc.org; Web page: www.INICC.org.
Division of Infection Control, Porto Alegre General Hospital, Porto Alegre, Brazil.

4 Division of Infection Control, Clementino Fraga Filho University Hospital, Rio de Janeiro, Brazil. 
Surveillance of healthcare-associated infections (HAI), particularly in the high-risk hospital setting found in intensive care units (ICU), has allowed United States hospitals to improve infection control and health care quality (1). Surveillance has proved effective in preventing $\mathrm{HAI}$, as documented in the U.S. Centers for Disease Control and Prevention (CDC) Study of the Efficacy of Nosocomial Infections Control (SENIC) (2). As a result of this evidence, standards for HAI surveillance and infection control have been developed and adopted in several industrialized countries (3).

There is increasing scientific evidence that HAIs are a major cause of patient morbidity and mortality in the industrialized world (4). Deviceassociated infections (DAIs), particularly ventilator-associated pneumonia (VAP), central venous catheter-related bloodstream infection (CVC-BSI), and catheter-associated urinary tract infection (CAUTI) pose the greatest threat to ICU patients (5-7).

Surveillance of DAIs has become uniform thanks to the introduction of the CDC's National Nosocomial Infection Surveillance System (NNIS), which provides clear, unambiguous definitions for DAIs (8). Calculating DAI rates per 1000 device-days and implementing targeted surveillance allows for effective comparative assessment of health care facilities, and provides a comprehensive overview of problems to be solved at specific institutions.

Most studies addressing ICUacquired infection have been published about health care in industrialized countries (9), but there is a lack of scientific data showing DAI rates in developing countries. Uniform definitions are needed to close this gap and to improve health care standards (10-15).

Brazil is the largest country in Latin America, and has the fifth largest population in the world. Health care facilities are beset with common health problems. These include, but are not limited to, deficiencies in infrastructure and a shortage of well-trained health care workers. Health facilities suffer from the widespread occurrence of multidrug-resistant Staphylococcus aureus and gram-negative bacteria.

Beginning in 1983, the Brazilian Ministry of Health has worked to establish a nation-wide program to control healthcare-associated infections (16). In 1994, the Ministry conducted a national study to evaluate how measures implemented for HAI control had affected HAI rates. The study concluded that there was a median incidence of $15.5 \%$ for HAI and that $42.5 \%$ of hospitals were engaged in appropriate infection control activities. The health sector was highly receptive to the HAI control program and the study reported an increase in the number of infection control committees in health facilities from $7 \%$ in 1992 to $43 \%$ in $1993(17,18)$.

Largely as a result of these initiatives, data for infection control conditions and HAI rates from Brazil are available (19). A study made in 1992 of a hospital in Belo Horizonte, Brazil, concluded that the global prevalence rate of HAI was $14.0 \%$. It also revealed that pneumonia and surgical-site infections (SSI) were responsible for $19.5 \%$ and $19.2 \%$ of HAIs, respectively (20). A group of hospitals, also in Belo Horizonte, that applied CDC-NNIS methods from January 1991 to June 1995 reported that the mean rate of HAI was $5.1 \%$ or 9.7 HAI per 1000 patient-days (21).

The objective of this study is to update data detecting DAI rates, microbiological profile, bacterial resistance, extra length of stay, and attributable mortality from a multi-center study carried out in three urban hospitals in Brazil.

\section{METHODS}

\section{Setting}

The International Nosocomial Infection Control Consortium (INICC) is a nonprofit organization founded in 1998 with the aim to prevent and reduce DAIs in hospitals in developing countries by collecting surveillance data on these infections. Hospitals that are INICC members provide general medical and surgical services to adults and children hospitalized in their intensive care units. INICC applies standardized protocols for data collection $(8,22)$.

This study was conducted from April 2003 to February 2006 in five ICUs of three INICC member hospitals in São Paulo, Porto Alegre, and Rio de Janeiro, Brazil. Identity of the participating hospitals remains confidential.

The infection control team at each hospital was comprised of a physician, an infection control practitionersurveillance (ICP) nurse, and support personnel. The person responsible for DAI surveillance in each institution had an average of six years experience in infection control (see Table 1). Every hospital maintained a clinical microbiology laboratory that provided standardized in vitro susceptibility testing of clinical isolates. Patients occupied beds in a common ward. The ICU nurse-to-patient ratio was one to three.

The research study protocol was approved by the Institutional Review Board at each health care facility. Patient confidentiality was protected by coding the recorded information, with patient identities known only to the institutional infection control team.

\section{Surveillance}

Each month, rates of CVC-BSI, CAUTI, and VAP were recorded, using definitions established by the CDC National Nosocomial Infections Surveillance System (NNIS) $(8,22)$.

\section{Definitions}

The following DAI definitions are adapted from those established by the CDC National Nosocomial Infections Surveillance System (NNIS) as reported in Garner et al. (8).

Ventilator-associated pneumonia (VAP). VAP is indicated in a mechanically ventilated patient with a chest radiograph that shows new or progressive infiltrates, consolidation, cavitation, or pleural effusion. The pa- 
TABLE 1. Features of three International Nosocomial Infection Control Consortium member hospitals in Brazil, April 2003 to February 2006

\begin{tabular}{|c|c|c|c|c|}
\hline Variable & Hospital A & Hospital B & Hospital C & Total \\
\hline Hospitals (number) & 1 & 1 & 1 & 3 \\
\hline Academic teaching & 0 & 1 & 0 & 1 \\
\hline Public & 1 & 0 & 0 & 1 \\
\hline Private community & 0 & 0 & 1 & 1 \\
\hline Hospital beds (number) & 750 & 480 & 180 & 1410 \\
\hline \multicolumn{5}{|l|}{ Experience of infection control } \\
\hline practitioners (years) & 6 & 14 & 9 & $6-14$ \\
\hline Intensive care units (ICUs) (number) & 3 & 1 & 1 & 5 \\
\hline ICU type & Medical-surgical & Medical-surgical & Medical-surgical & Medical-surgical \\
\hline ICU beds (number) & 35 & 14 & 9 & 58 \\
\hline Surveillance period & $10 / 03$ to $10 / 04$ & $4 / 03$ to $6 / 03$ & $6 / 04$ to $2 / 06$ & $4 / 03$ to $2 / 06$ \\
\hline Patients studied (number) & 705 & 142 & 184 & 1031 \\
\hline Total ICU days & 7942 & 673 & 1678 & 10293 \\
\hline Male (\%) & 55.3 & 52.8 & 50.5 & 54.1 \\
\hline Mean age of patient (years) & 53.6 & 55.7 & 68.1 & 56.5 \\
\hline Mean ASISa & 3.59 & 2.57 & 3.90 & 3.51 \\
\hline \multicolumn{5}{|l|}{ Device utilization (DU) ${ }^{\mathrm{b}}$} \\
\hline Ventilator-days & 5344 & 424 & 734 & 6502 \\
\hline Ratio of ventilator use & 0.67 & 0.63 & 0.44 & 0.63 \\
\hline Central venous catheter-days & 7648 & 620 & 1226 & 9494 \\
\hline Ratio of central venous catheter use & 0.96 & 0.92 & 0.73 & 0.92 \\
\hline Urinary catheter-days & 6768 & 619 & 1430 & 8817 \\
\hline Ratio of urinary catheter use & 0.85 & 0.92 & 0.85 & 0.86 \\
\hline
\end{tabular}

tient must also meet at least one of the following criteria: new onset of purulent sputum or change in character of sputum; organism cultured from blood; or isolation of an etiologic agent from a specimen obtained by tracheal aspirate, bronchial brushing or bronchoalveolar lavage, or biopsy.

Laboratory-confirmed central venous catheter-associated bloodstream infection (CVC-BSI). Central venous catheter-associated bloodstream infection is laboratory-confirmed when a patient with a CVC has a recognized pathogen that is isolated from one or more percutaneous blood cultures after 48 hours of vascular catheterization and is not related to an infection at another site. The patient also has at least one of the following signs or symptoms: fever (temperature $\geq 38^{\circ} \mathrm{C}$ ), chills, or hypotension. With skin commensals (for example, diphtheroids, Bacillus spp., Propionibacterium spp., coagulase-negative staphylococci, or micrococci), the organism is cultured from two or more blood cultures.
Clinically suspected central venous catheter-associated bloodstream infection (CVC-BSI). Central venous catheter-associated bloodstream infection is clinically suspected when a patient with a CVC has at least one of the following clinical signs with no other recognized cause: fever (temperature $\geq 38{ }^{\circ} \mathrm{C}$ ), hypotension (systolic blood pressure $\leq 90 \mathrm{mmHg}$ ), or oliguria $(\leq 20 \mathrm{~mL} / \mathrm{h})$.

Catheter-associated urinary tract infection (CAUTI). For the diagnosis of catheter-associated urinary tract infection, the patient must meet one of two criteria. The first criterion is satisfied when a patient with a urinary catheter has one or more of the following symptoms with no other recognized cause: fever (temperature $\geq 38^{\circ} \mathrm{C}$ ), urgency, or suprapubic tenderness. The urine culture is positive for $10^{5}$ colony-forming units (CFU) per $\mathrm{mL}$ or more, with no more than two microorganisms isolated. The second criterion is satisfied when a patient with a urinary catheter has at least two of the following criteria with no other recognized cause: positive dipstick analysis for leukocyte esterase or nitrate and pyuria ( $\geq 10$ leukocytes $/ \mathrm{mL}$ ).

\section{Culture techniques}

In all cases, standard laboratory methods were used to identify microorganisms, and a standardized susceptibility test was performed (23). The following are culture techniques for VAP, CVC-BSI, and CAUTI.

VAP. In most cases, a deep tracheal aspirate from the endotracheal tube was cultured aerobically and gram-stained.

CVC-BSI. Central venous catheters were removed aseptically and the distal $5 \mathrm{~cm}$ of the catheter was amputated and cultured using a standardized, semiquantitative method (24). Concomitant blood cultures were drawn percutaneously in nearly all cases. 
CAUTI. A urine sample was aseptically aspirated from the sampling port of the urinary catheter and cultured quantitatively.

\section{Forms, training, adjudication, and data feedback}

Surveillance data were prospectively and actively collected using forms that were specially designed to allow adjudication of DAIs. Data forms were based on the new onset of fever, beginning of antibiotic therapy, performance of cultures, and presentation of hypotension 48 hours after admission. At each ICU, a patient had a check-off for every clinical and microbiologic criterion for each type of DAI. This allowed the hospital epidemiologist or other senior infection control officer reviewing completed data forms in the participating hospital to confirm that in each case adequate criteria for infection were met. Additionally, the original patient data form could be further assessed at the INICC headquarters in Buenos Aires before the reported infection was registered in the consortium database (10).

Data on patient demographics, age, gender, severity of illness score, and hospital location were gathered at the beginning of hospitalization. Each day, the infection control practitioner (ICP) prospectively and actively collected data on mechanical ventilation, placement of CVC and urinary catheters, fever, blood pressure, antibiotic use, and the results of cultures on each patient admitted to the ICU. At the end of hospitalization, if the patient had acquired a DAI, the ICP recorded the date of onset, site of infection, infecting microorganisms, and their antimicrobial susceptibilities.

The average severity-of-illness score (ASIS) was recorded by applying the CDC Nosocomial Infections Surveillance System criteria. Points were ascribed to patients as follows: 1 point for postoperative patients requiring routine postoperative observation; 2 points for physiologically stable patients requiring prophylactic overnight observation; 3 points for patients requiring nursing and monitoring; 4 points for physiologically unstable patients requiring intensive nursing and medical care with the need for frequent reassessment and adjustment of therapy; and 5 points for physiologically unstable patients in coma or shock, who require cardiopulmonary resuscitation, or who need intensive medical and nursing care with frequent reassessment (22).

At each member hospital, researchers received training about surveillance procedures from the INICC Chairman (VDR). A support team at INICC headquarters in Buenos Aires answered questions from the investigators in Brazilian facilities within 24 hours; these responses were in turn reviewed by the INICC Chairman (10).

Each month the completed surveillance forms from participating hospital were sent to INICC headquarters in Buenos Aires. To ensure that criteria for DAIs met those established by CDC NNIS, each form was assessed in terms of registered signs (fever, blood pressure), cultures, device use, and consumption of antibiotics $(8,22)$.

The DAIs reported by the hospitals were adjudicated, i.e., scrutinized to ensure that sufficient criteria had been met to record them as DAIs. This included examination of data for putatively uninfected patients to detect any unreported DAIs. When discrepancies were encountered, the INICC contacted the hospital research teams via electronic mail; the judgement of the principal investigator and ICP of the participating hospital was final. Adjudication is a unique feature of the INICC outcome surveillance component and is considered essential not only to maximize the accuracy of surveillance data, but also to continually assess the capacity of the ICP and principal investigator at each hospital.

Each month, the INICC team prepared individual reports for each participating hospital. These reports contained updated data, presented in charts and tables, showing the hospitals' DAI rates, microbiological profile, bacterial resistance, extra mortality by type of DAI, extra length of stay (LOS), hand hygiene compliance, and CVC and urinary catheter care compliance.

\section{Statistical analysis}

Outcomes measured during the surveillance period included the incidence density rate of CVC-BSI, CAUTI, and VAP. The DAI rates per 1000 devicedays were calculated by dividing the total number of DAIs by the total number of specific device-days and multiplying the result by 1000 (22).

Device utilization (DU) ratios were calculated by dividing the total number of device-days by the total number of patient-days. Device-days are the total number of days of exposure to the device (central line, ventilator, or urinary catheter) by all of the patients in the selected population during the selected time period. Patient-days are the total number of days that patients are in the ICU during the selected time period.

Chi square analyses for dichotomous variables and t-test for continuous variables were used to analyze baseline differences among rates. Relative risk (RR) ratios, 95\% confidence intervals (CIs), and $P$-values were determined for all primary and secondary outcomes.

The crude excess mortality was calculated as the difference between the crude mean case-fatality of patients with a device-associated infection and the crude case-fatality of patients hospitalized in the ICU during the same period who did not acquire a device-associated infection. The extra length of stay (LOS) is the difference between the length of stay of patients with a DAI and the length of stay of patients hospitalized in the ICU during the same period who did not acquire a DAI.

Epilnfo $^{\circledR}$ version $6.04 \mathrm{~b}$ (CDC, Atlanta, Georgia) was used to conduct data analysis.

\section{RESULTS}

During the study period (April 2003 to February 2006), surveillance data were collected prospectively on 1031 patients hospitalized for an aggregate of 10293 ICU-days in five ICUs in three hospitals in Brazil. The features of each ICU, the number of patients enrolled, ICU-days, and the average 
TABLE 2. DAIs ${ }^{\mathrm{a}}$ per 1000 device-days in $\mathrm{ICUs}^{\mathrm{a}}$ of three Brazilian International Nosocomial Infection Control Consortium member hospitals, April 2003 to February 2006

\begin{tabular}{|c|c|c|c|c|c|c|}
\hline Infection & $\begin{array}{l}\text { Device } \\
\text { type }\end{array}$ & Device-days & $\begin{array}{l}\text { DAls } \\
(n)\end{array}$ & $\begin{array}{l}\text { Distribution } \\
\text { of DAls (\%) }\end{array}$ & $\begin{array}{c}\text { Rate per } \\
100 \\
\text { patients } \\
(\%)\end{array}$ & $\begin{array}{c}\text { Rate per } \\
1000 \\
\text { device-days } \\
(\%)^{b}\end{array}$ \\
\hline VAPa & $\mathrm{MV}^{\mathrm{a}}$ & 6502 & 254 & 44.3 & 13.2 & 20.9 \\
\hline CVC-BSI ${ }^{a}$ & $\mathrm{CVC}^{\mathrm{a}}$ & 9494 & 26 & 28.0 & 8.3 & 9.1 \\
\hline CAUTIa & $\mathrm{UC}^{\mathrm{a}}$ & 8817 & 27 & 27.7 & 8.2 & 9.6 \\
\hline
\end{tabular}

DAI: Device-associated infection; ICU: intensive care unit; VAP: ventilator-associated pneumonia, CVC-BSI: central vascular catheter-associated blood stream infection; CAUTI: catheter-associated urinary tract infection; MV: mechanical ventilator; UC: urinary catheter.

${ }^{b}$ Rate per 1000 device-days: Rates were calculated by dividing the total number of DAls by the total number of specific devicedays by all of the patients in the selected population during the selected time period and multiplying the result by 1000 . severity-of-illness score (ASIS) are shown in Table 1 (24). Mean patient ASIS was 3.51.

Patients acquired 307 DAIs for a mean rate of $29.8 \%$ or 29.8 infections per 1000 ICU-days. CVC-associated BSI represented $28.0 \%$, VAP represented $44.3 \%$, and CAUTI represented $27.7 \%$ of all DAIs (Table 2).

TABLE 3. Microbiological profile of DAls ${ }^{\mathrm{a}}$ in the ICUs ${ }^{\mathrm{a}}$ of three International Nosocomial Infection Control Consortium member hospitals in Brazil, April 2003 to February 2006

\begin{tabular}{lc}
\hline \multicolumn{1}{c}{ Pathogen } & $\begin{array}{c}\text { Proportion of } \\
\text { cases (\%) }\end{array}$ \\
\hline Enterobacteriaceae & 22.8 \\
Pseudomonas spp. & 22.6 \\
Candida spp. & 15.9 \\
Acinetobacter spp. & 14.6 \\
Staphylococcus aureus & 11.3 \\
Coagulase-negative & \\
$\quad$ staphylococci & 8.4 \\
Enterococcus spp. & 2.5 \\
Stenotrophomonas spp. & 0.8 \\
Streptococcus spp. & 0.8 \\
\hline
\end{tabular}

a DAI: Device-associated infection; ICU: intensive care unit.

\section{Device utilization ratio}

Device utilization ratio presented a wide range: mechanical ventilation utilization ratio ranged from 0.44 to 0.67 (mean, 0.63); CVC utilization ratio ranged from 0.73 to 0.96 (mean, 0.92 ); and urinary catheter utilization ratio ranged from 0.85 to 0.92 (mean, 0.86) (Table 1). Distribution by type of deviceassociated infection and device utilization are shown in Table 2.

\section{VAP}

The rates of VAP ranged from 16.3 to 21.9 per 1000 ventilator-days, with a mean rate in the five ICUs of 20.9 per 1000 ventilator-days (Table 2). Crude mortality of patients with VAP was $34.5 \%$, with an extra mortality of $15.3 \%$, (RR $1.79,95 \%$ CI $1.11-2.89, P=0.0149$ ). The LOS of patients without DAI was 5.8 days, and the LOS of patients with VAP was 16.8 days, yielding an extra length of stay of 11.0 days (RR 2.91,95\% CI 2.72-3.13, $P<0.001)$.
TABLE 4. Resistance of pathogens in the ICUs ${ }^{\mathrm{a}}$ of three International Nosocomial Infection Control Consortium member hospitals in Brazil, April 2003 to February 2006

\begin{tabular}{llc}
\hline \multicolumn{1}{c}{ Bacteria } & \multicolumn{1}{c}{ Antibiotic used } & Percentage resistance \\
\hline Enterobacteriaceae & Ceftriaxone & 96.7 \\
Enterobacteriaceae & Ceftazidime & 79.3 \\
Enterobacteriaceae & Piperacillin-tazobactam & 85.7 \\
Enterococci & Vancomycin & 0.0 \\
Pseudomonas aeruginosa & Ciprofloxacin & 71.3 \\
Pseudomonas aeruginosa & Ceftazidime & 75.5 \\
Pseudomonas aeruginosa & Imipenem & 27.7 \\
Pseudomonas aeruginosa & Piperacillin-tazobactam & 100 \\
Staphylococcus aureus & Methicillin & 95.7 \\
\hline
\end{tabular}

a ICU: Intensive care unit.

\section{CVC-associated BSI}

The rates of BSI varied widely, from 8.1 to 25.8 per 1000 catheter-days, with a mean rate of 9.1 per 1000 catheter-days (Table 2). The crude mortality of patients with BSI was $47.1 \%$, with an extra mortality of $27.8 \%$ (RR 2.44, 95\% CI 1.46-4.09, $P=0.0004$ ). The LOS of patients with CVC-BSI was 13.0 days, yielding an extra length of stay of 7.3 days (RR 2.26, 95\% CI 2.05-2.49, $P<0.001)$.

\section{CAUTI}

The rates of CAUTI ranged from 4.8 to 11.1 per 1000 catheter-days, with a mean rate of 9.6 per 1000 catheter-days (Table 2). Crude mortality of patients with CAUTI was $30.0 \%$, with extra mortality of $10.7 \%$ (RR $1.56,95 \%$ CI 0.69 $3.52, P=0.2875)$. The LOS of patients with CAUTI was 14.1 days, yielding an extra length of stay of 8.3 days (RR 2.44, 95\% CI 2.17-2.76, $P<0.001$ ).

\section{Bacterial profile and resistance}

The most common agents that caused DAIs were Enterobacteriaceae (22.8\%), Pseudomonas spp (22.6\%), Candida spp. (15.9\%), and Acinetobacter spp. (14.6\%). Staphylococcus aureus (11.3\%) and coagulase-negative staphylococci $(8.4 \%)$ were also significant (see Table 3). The drug resistance of these pathogens to antibiotics is illustrated in Table 4.

\section{DISCUSSION}

Healthcare-associated infections (HAIs) continue to be a major cause of patient morbidity and attributable mortality (4). In addition, health care costs are significantly increased by HAIs (4, 25-27). It should be noted that the incidence of HAIs can be reduced by as much as $30 \%$, which would result in a substantial decline in health care costs. This is supported by studies conducted in U.S. hospitals where integrated infection control programs, including targeted surveillance of 
device-associated infections, have been implemented (2).

In INICC member hospitals, surveillance is conducted by the use of forms specially designed to gather patient data, including patients with and without DAIs. These forms provide the ICPs with prompts at every stage of treatment, and enable them to detect the occurrence of DAIs. The data contained in the forms include patient's temperature, blood pressure, exposure to invasive devices, cultures done, and antibiotic use, providing for an uninterrupted and comprehensive picture of the patient's condition in the ICU. The forms make it possible to compare patients in terms of age, gender, underlying diseases, service (medical or surgical), severity-ofillness score, time of year, and exposure to invasive devices. INICC uses this information to calculate the added length of stay (LOS) and resulting hospitalization costs and attributable mortality (10, 12-15, 26-29).

The INICC's initial efforts have focused on surveillance in ICUs because of the extensive use of invasive devices where patients are exposed to higher rates of DAIs (3). External adjudication applied by the INICC results in increased accuracy regarding infections reported. In most cases, DAIs in ICUs as defined by the CDC-NNIS System and the INICC databases are based on positive cultures. Therefore, it is reasonable to assume that the difference between the surveillance methodology implemented by the CDC-NNIS and the INICC in their ability to detect the majority of DAIs is not significant.

Hand hygiene resources and compliance showed significant variation in INICC member hospitals and ICUs, ranging from $20 \%$ to $70 \%$ (30). The mean rate of hand hygiene compliance in a recent study carried out in the participating ICUs of all INICC member hospitals was 50\% (30). This was similar to results of recent research studies conducted in the United States and Europe (31). Significant variation was also found in the use of sterile dressings on CVC insertion sites in Peruvian INICC member hospitals. Among the major obstacles to be overcome at hospitals with limited resources are: poor hand hygiene compliance, the ineffective isolation of patients, protracted use of invasive devices, and the incorrect positioning of the urine collection bag (32).

We compared DAI rates in this study of five ICUs in INICC member hospitals in Brazil with pooled rates for DAIs in the ICUs of U.S. hospitals included in the CDC's National Healthcare Safety Network (CDCNHSN) survey results for 2005-2006 (1). In the five ICUs in INICC member hospitals in Brazil, the mean rate for CVC-BSI was 9.1 per 1000 catheterdays compared with a rate of 2.4 per 1000 CVC-days reported in the CDCNHSN study; the mean rate for VAP was 20.9 per 1000 ventilator-days in the Brazilian study compared with a rate of 3.6 per 1000 ventilator-days reported in the CDC-NHSN study; the rate for CAUTI was 9.6 per 1000 catheter days in the Brazilian study compared with the CDC-NHSN rate of 3.4 per 1000 catheter-days (1).

In the Brazilian INICC ICUs, crude mortality from VAP was $34.5 \%$, with an extra mortality of patients with VAP of $15.3 \%$, significantly higher than patients without DAI. The crude mortality of patients with BSI was $47.1 \%$, with extra mortality of $27.8 \%$, also significantly higher than patients without DAI. However, the extra mortality of patients with CAUTI was $10.7 \%$, which shows no significant difference when comparing patients without DAI. These results are similar to the findings of Clec'h et al. who conducted a study from 1995 to 2007 and analyzed data of 298 patients with CAUTI. After matching patients with and without CAUTI, it was determined that CAUTI was not associated with increased mortality (33).

There was a high rate of resistance to most antibiotics commonly used in ICUs (Table 4). This may be the result of inadequate infection control programs as well as clonal spread of resistance among patients. Control of antibiotic resistance requires more restrictive use of anti-infective agents, isolation of patients, and more effective DAI control (34). Additionally, control of antibiotic resistance might involve active surveillance of admitted patients, as some DAIs are community-acquired infections which colonize in patients and become institutionalized (34).

Some of the factors affecting high DAI rates in Brazilian ICUs included in this study have been addressed in other studies conducted in developing countries $(20,21)$. First, it should be taken into account that most developing countries lack the legal framework or standards governing the implementation of infection control programs. In the few cases where infection control standards are in force, compliance is lacking. Additionally, hospital accreditation and national infection control surveillance are not compulsory. Second, hand hygiene compliance in most health care facilities presents highly variable rates $(30,35,36)$. Third, the great majority of hospitals in developing countries receive limited financial or administrative support, resulting in a scarcity of necessary funds to deal with infection control (37). Fourth, the low nurse-to-patient staffing ratio in hospitals in developing countries compared with hospitals in industrialized countries is one of the factors contributing to the high DAI rates in ICUs (38). This situation is exacerbated by the fact that wards are over-crowded, nurses lack experience, there is a shortage of trained personnel, and supplies are lacking.

DAI surveillance is the first measure to be taken to reduce the threat of DAIs in hospitalized patients (2). Next, basic infection control should be practiced for effective prevention of DAIs $(39,40)$. There is evidence that significant improvement occurs in health facilities where efforts are made to impart awareness and knowledge about the problem of DAIs in their ICUs. Feedback programs for hand hygiene compliance show substantially lowered rates in healthcare-associated infections. In several of the INICC member hospitals there is evidence that attention to the use of CVC and urinary catheters has brought about significant declines in the incidence of DAIs $(28,35,36,41-44)$. 


\section{Limitations}

This study has several limitations. First, the data collected during the three-year study are not generally representative of all of Brazil's health care facilities. They do represent, however, comprehensive surveillance of five ICUs in three hospitals in three cities, so the study's findings are useful for the design of infection control strategies. Second, APACHE severity-ofillness scores were not used because there were not enough resources for the labor-intensive calculation of this score. Finally, similar to other cohort studies, hospitals initiated clinical surveillance at different periods and surveillance was suspended at certain times, resulting in the lack of simultaneously collected data from all hospitals enrolled in this study.

1. Edwards JR, Peterson KD, Andrus ML, Tolson JS, Goulding JS, Dudeck MA, et al. National Healthcare Safety Network (NHSN) Report, data summary for 2006, issued June 2007. Am J Infect Control. 2007;35(5):290-301.

2. Hughes JM. Study on the efficacy of nosocomial infection control (SENIC Project): results and implications for the future. Chemotherapy. 1988;34(6):553-61.

3. National Nosocomial Infections Surveillance (NNIS) System Report, data summary from January 1992 through June 2004, issued October 2004. Am J Infect Control. 2004;32(8):470-85.

4. Jarvis WR. Selected aspects of the socioeconomic impact of nosocomial infections: morbidity, mortality, cost, and prevention. Infect Control Hosp Epidemiol. 1996;17(8):552-7.

5. Fagon JY, Novara A, Stephan F, Girou E, Safar M. Mortality attributable to nosocomial infections in the ICU. Infect Control Hosp Epidemiol. 1994;15(7):428-34.

6. Fagon JY, Chastre J, Vuagnat A, Trouillet JL, Novara A, Gibert C. Nosocomial pneumonia and mortality among patients in intensive care units. JAMA. 1996;275(11):866-9.

7. Digiovine $B$, Chenoweth $C$, Watts $C$, Higgins $\mathrm{M}$. The attributable mortality and costs of primary nosocomial bloodstream infections in the intensive care unit. Am J Respir Crit Care Med. 1999;160(3):976-81.

8. Garner JS, Jarvis WR, Emori TG, Horan TC, Hughes JM. CDC definitions for nosocomial infections, 1988. Am J Infect Control. 1988; 16(3):128-40.

9. Safdar N, Crnich CJ, Maki DG. Nosocomial infections in the intensive care unit associated with invasive medical devices. Curr Infect Dis Rep. 2001;3(6):487-95.

10. Rosenthal VD, Maki DG, Salomao R, Moreno CA, Mehta Y, Higuera F, et al. Device-associ-

\section{Conclusion}

Healthcare-associated infections pose a huge and under-recognized threat to patient safety in developing countries. It is hoped that interventions such as the surveillance of DAIs described in this study, together with simple and inexpensive infection prevention measures already being implemented, will lead to broad acceptance of infection control programs in all INICC member hospitals. This would significantly reduce all types of DAIs, particularly those acquired in ICUs.

Acknowledgments. The authors thank the many health care professionals at each INICC member hospital who assisted with surveillance in their

\section{REFERENCES}

ated nosocomial infections in 55 intensive care units of 8 developing countries. Ann Intern Med. 2006;145(8):582-91.

11. Rosenthal VD, Guzman S, Crnich C. Deviceassociated nosocomial infection rates in intensive care units of Argentina. Infect Control Hosp Epidemiol. 2004;25(3):251-5.

12. Rosenthal VD, Guzman S, Orellano PW, Safdar N. Nosocomial infections in medical-surgical intensive care units in Argentina: attributable mortality and length of stay. Am J Infect Control. 2003;31(5):291-5.

13. Ramirez Barba EJ, Rosenthal VD, Higuera F, Oropeza MS, Hernandez HT, Lopez MS, et al. Device-associated nosocomial infection rates in intensive care units in four Mexican public hospitals. Am J Infect Control. 2006;34(4):244-7.

14. Moreno CA, Rosenthal VD, Olarte N, Gomez WV, Sussmann O, Agudelo JG, et al. Deviceassociated infection rate and mortality in intensive care units of 9 Colombian hospitals: findings of the International Nosocomial Infection Control Consortium. Infect Control Hosp Epidemiol. 2006;27(4):349-56.

15. Leblebicioglu H, Rosenthal VD, Arikan OA, Ozgultekin A, Yalcin AN, Koksal I, et al. Device-associated hospital-acquired infection rates in Turkish intensive care units. Findings of the International Nosocomial Infection Control Consortium (INICC). J Hosp Infect. 2007; 65(3):251-7.

16. Pannuti CS, Grinbaum RS. An overview of nosocomial infection control in Brazil. Infect Control Hosp Epidemiol. 1995;16(3):170-4.

17. da Silva RF. [Hospital infection in the context of health policies instituted by the state of Santa Catarina]. Rev Lat Am Enfermagem. 2003;11(1):108-14.

18. Lacerda RA, Jouclas VM, Egry EY. [Hospital infections in Brazil. Government actions for respective facilities, including the surveillance nurses, clinical microbiology laboratory personnel, and the physicians and nurses providing care for the patients during the study, without whose cooperation and generous assistance this study would not have been possible. The authors also thank the INICC country coordinators (Altaf Ahmed, Carlos A. Alvarez-Moreno, Luis E. Cuellar, Eduardo A. Medeiros, Bijie Hu, Hakan Leblebicioglu, Ajita P. Mehta, Lul Raka, and Toshihiro Mitsuda), and the INICC Advisory Board (Carla J. Alvarado, Martin S. Favero, Gary L. French, Nicholas Graves, William R. Jarvis, Elaine Larson, Patricia Lynch, Dennis Maki, Russell N. Olmsted, Didier Pittet, and Wing Hong Seto), who have so generously supported this unique international infection control network. their control as expressions of social politics in the health area]. Rev Esc Enferm USP. 1996; 30(1):93-115.

19. Lobo RD, Levin AS, Gomes LM, Cursino R, Park M, Figueiredo VB, et al. Impact of an educational program and policy changes on decreasing catheter-associated bloodstream infections in a medical intensive care unit in Brazil. Am J Infect Control. 2005;33(2):83-7.

20. Rezende EM, Couto BR, Starling CE, Modena $\mathrm{CM}$. Prevalence of nosocomial infections in general hospitals in Belo Horizonte. Infect Control Hosp Epidemiol. 1998;19(11):872-6.

21. Starling CE, Couto BR, Pinheiro SM. Applying the Centers for Disease Control and Prevention and National Nosocomial Surveillance system methods in Brazilian hospitals. Am J Infect Control. 1997;25(4):303-11.

22. Emori TG, Culver DH, Horan TC, Jarvis WR, White JW, Olson DR, et al. National Nosocomial Infections Surveillance system (NNIS): description of surveillance methods. Am J Infect Control. 1991;19(1):19-35.

23. National Committee for Clinical Laboratory Standards (NCCLS). Approved standard M7A4: methods for dilution antimicrobial susceptibility tests for bacteria that grow aerobically. 4th ed. Wayne, Pennsylvania: National Committee for Clinical Laboratory Standards, 1997.

24. Maki DG, Weise CE, Sarafin HW. A semiquantitative culture method for identifying intravenous-catheter-related infection. N Engl J Med. 1977;296(23):1305-9.

25. Pittet D, Tarara D, Wenzel RP. Nosocomial bloodstream infection in critically ill patients. Excess length of stay, extra costs, and attributable mortality. JAMA. 1994;271(20):1598-601.

26. Rosenthal VD, Guzman S, Migone O, Safdar $\mathrm{N}$. The attributable cost and length of hospital stay because of nosocomial pneumonia in in- 
tensive care units in 3 hospitals in Argentina: a prospective, matched analysis. Am J Infect Control. 2005;33(3):157-61.

27. Rosenthal VD, Guzman S, Migone O, Crnich CJ. The attributable cost, length of hospital stay, and mortality of central line-associated bloodstream infection in intensive care departments in Argentina: A prospective, matched analysis. Am J Infect Control. 2003;31(8):475-80.

28. Higuera F, Rosenthal VD, Duarte P, Ruiz J, Franco G, Safdar N. The effect of process control on the incidence of central venous catheter-associated bloodstream infections and mortality in intensive care units in Mexico. Crit Care Med. 2005;33(9):2022-7.

29. Higuera F, Rangel-Frausto MS, Rosenthal VD, Martinez Soto J, Castañon J, Franco G, et al. Attributable cost and length of stay for patients with central venous catheter-associated bloodstream infection in Mexico City intensive care units: a prospective, matched analysis. Infect Control Hosp Epidemiol. 2007;28(1):31-5.

30. Rosenthal VD, Salomao R, Leblebicioglu H, Akan O, Sobreyra-Oropeza M. Hand hygiene compliance in Argentina, Brazil, Colombia, India, Mexico, Morocco, Peru and Turkey. Findings of the International Nosocomial Infection Control Consortium (INICC). In: Proceedings and Abstracts of the 33rd Annual Scientific Meeting of the Association for Professionals in Infection Control and Epidemiology; 11-15 June 2006; Tampa, Florida, United States of America;. p. 31.

31. Pittet D. Compliance with hand disinfection and its impact on hospital-acquired infections. J Hosp Infect. 2001;48 (Suppl A):S40-6.

32. Koksal I, Aydin K, Caylan R, Leblebicioglu H, Rosenthal VD. Effect of education and performance feedback on handwashing in a hospital of Trabzon, Turkey. In: Proceedings and Abstracts of the 15th Annual Scientific Meeting of the Society for Healthcare Epidemiology of America; 9-12 April 2005; Los Angeles, California, United States of America; p. 90.

33. Clec'h C, Schwebel C, Francais A, Toledano D, Fosse JP, Garrouste-Orgeas M, et al. Does catheter-associated urinary tract infection increase mortality in critically ill patients? Infect Control Hosp Epidemiol. 2007;28(12):1367-73.

34. Safdar N, Maki DG. The commonality of risk factors for nosocomial colonization and infection with antimicrobial-resistant Staphylococcus aureus, enterococcus, gram-negative bacilli, Clostridium difficile, and Candida. Ann Intern Med. 2002;136(11):834-44.

35. Rosenthal VD, Guzman S, Safdar N. Reduction in nosocomial infection with improved hand hygiene in intensive care units of a tertiary care hospital in Argentina. Am J Infect Control. 2005;33(7):392-7.

36. Rosenthal VD, McCormick RD, Guzman S, Villamayor C, Orellano PW. Effect of education and performance feedback on handwashing: the benefit of administrative support in Argentinean hospitals. Am J Infect Control. 2003;31(2):85-92.

37. Chandra PN, Milind K. Lapses in measures recommended for preventing hospital-acquired infection. J Hosp Infect. 2001;47(3): 218-22.

38. Hugonnet S, Harbarth S, Sax H, Duncan RA, Pittet D. Nursing resources: a major determinant of nosocomial infection? Curr Opin Infect Dis. 2004;17(4):329-33.

39. O'Grady NP, Alexander M, Dellinger EP, Gerberding JL, Heard SO, Maki DG, et al. Guidelines for the prevention of intravascular catheter-related infections. Am J Infect Control. 2002;30(8):476-89.
40. Boyce JM, Pittet D. Guideline for hand hygiene in Health-Care Settings. Recommendations of the Healthcare Infection Control Practices Advisory Committee and the HICPAC/ SHEA/APIC/IDSA Hand Hygiene Task Force. Society for Healthcare Epidemiology of America/Association for Professionals in Infection Control/Infectious Diseases Society of America. MMWR Recomm Rep. 2002;51(RR16):1-45, quiz CE1-4.

41. Rosenthal VD, Maki DG. Prospective study of the impact of open and closed infusion systems on rates of central venous catheterassociated bacteremia. Am J Infect Control. 2004;32(3):135-41.

42. Rosenthal VD, Guzman S, Safdar N. Effect of education and performance feedback on rates of catheter-associated urinary tract infection in intensive care units in Argentina. Infect Control Hosp Epidemiol. 2004;25(1):47-50.

43. Rosenthal VD, Guzman S, Pezzotto SM, Crnich CJ. Effect of an infection control program using education and performance feedback on rates of intravascular deviceassociated bloodstream infections in intensive care units in Argentina. Am J Infect Control. 2003; 31(7):405-9.

44. Rosenthal VD, Guzman S, Crnich C. Impact of an infection control program on rates of ventilator-associated pneumonia in intensive care units in 2 Argentinean hospitals. Am J Infect Control. 2006;34(2):58-63.

Manuscript received on 30 January 2007. Revised version accepted for publication on 19 February 2008.
RESUMEN

Tasa de infecciones asociadas
a aparatos en unidades
de cuidados intensivos
de hospitales brasileños:
datos de la Comunidad
Científica Internacional de
Control de Infecciones
Nosocomiales

Palabras clave
Objetivos. Determinar las tasas de infección asociadas a aparatos (IAA), los perfiles microbiológicos, la resistencia bacteriana, la estancia hospitalaria adicional y la mortalidad atribuible en las unidades de cuidados intensivos (UCI) de tres hospitales brasileños miembros de la Comunidad Científica Internacional de Control de Infecciones Nosocomiales (INICC).

Métodos. Se realizó una vigilancia prospectiva de cohorte de las IAA en cinco UCI de tres hospitales urbanos de Brasil, según las definiciones del Sistema Nacional de Vigilancia de Infecciones Nosocomiales de los Centros para el Control y la Prevención de Enfermedades (CDC-NNIS) de los Estados Unidos de América.

Resultados. Entre abril de 2003 y febrero de 2006 se hospitalizaron 1031 pacientes en las cinco UCI estudiadas, con un total de 10293 días en los que se adquirieron 307 IAA, para una tasa de 29,8\% (29,8 IAA por 1000 días-UCI). Las tasas fueron: de 20,9 casos por 1000 díasventilador en neumonía asociada a respiradores (NAR); de 9,1 por 1000 días-catéter en infecciones circulatorias asociadas con cateterismo venoso central (IC-CVC); y de 9,6 por 1000 días-catéter en infecciones urinarias asociadas con el uso de catéteres (IUAC). De las IAA causadas por Staphylococcus aureus, $95 \%$ se debieron a cepas resistentes a la meticilina. De las infecciones causadas por Enterobacteriaceae, 96,7\% fueron resistentes a la ceftriaxona, 79,3\% a la ceftazidima y $85,7 \%$ a la combinación piperacilina-tazobactam. De las IAA causadas por Pseudomonas aeruginosa, 71,3\% resultaron resistentes a la ciprofloxacina, 75,5\% a la ceftazidima y $27,7 \%$ al imipenem. Los pacientes con IAA en las UCI estudiadas presentaron tasas de mortalidad adicional de 15,3\% (riesgo relativo $[R R]=1,79 ; P=0,0149)$ por $N A R, 27,8 \%(R R=$ $2,44 ; P=0,0004)$ por IC-CVC y $10,7 \%(\mathrm{RR}=1,56 ; P=0,2875)$ por IUAC.

Conclusiones. Las tasas de IAA en las UCI de los hospitales brasileños estudiados fueron elevadas. Se puede mejorar la seguridad de los pacientes mediante la implementación de un programa de control activo de las infecciones, que contemple la vigilancia de las IAA y directivas para la prevención de las infecciones. Estas acciones deben ser una prioridad en todos los países.

Infecciones bacterianas, infección hospitalaria/epidemiología, farmacorresistencia bacteriana, hospitales, control de infecciones, profesionales para control de infecciones, unidades de terapia intensiva, tiempo de internación, mortalidad, Brasil. 